\title{
BMJ Open Comparison of drug coverage in Canada before and after the establishment of the pan-Canadian Pharmaceutical Alliance
}

\author{
Debbie Milliken, ${ }^{1}$ Jaya Venkatesh, ${ }^{2}$ Rebecca Yu, ${ }^{3}$ Zhuo Su, ${ }^{4}$ Melissa Thompson, ${ }^{4}$ \\ Dean Eurich ${ }^{5}$
}

To cite: Milliken D,

Venkatesh J, Yu R, et al. Comparison of drug coverage in Canada before and after the establishment of the panCanadian Pharmaceutical Alliance. BMJ Open 2015;5: e008100. doi:10.1136/ bmjopen-2015-008100

- Prepublication history and additional material is available. To view please visit the journal (http://dx.doi.org/ 10.1136/bmjopen-2015008100).

Received 4 March 2015

Revised 17 July 2015

Accepted 24 July 2015

CrossMark

For numbered affiliations see end of article.

Correspondence to

Dr Dean Eurich;

deurich@ualberta.ca

\section{ABSTRACT}

Objectives: This study was conducted to determine whether establishment of the pan-Canadian

Pharmaceutical Alliance (pCPA) was associated with significant changes in drug listing decisions across Canada.

Analysis and results: This study included drug indications that received a Common Drug Review or pan-Canadian Oncology Drug Review listing recommendation within 3 years before ('pre-PCPA era' group; $n=79$ ) and 3 years after ('PCPA era' group; $n=91$ ) the $p C P A$ was established in August 2010. At the time of this study (30 April 2014), nine pCPAparticipating jurisdictions had listed $35-59 \%$ of drug indications in the pre-pCPA era group and a nearly identical range, $36-59 \%$, in the $\mathrm{PCPA}$ era group. Within the pCPA-era group, 31 drug indications (34\%) had completed pCPA negotiations ('pCPA negotiation' subgroup); the jurisdictions had listed $39-77 \%$ of these drug indications. Comparison of the pCPA era group to the pre-pCPA era group indicated that the proportion listed did not change significantly in any jurisdiction, and time-to-listing increased significantly in New Brunswick and decreased significantly in Alberta, Manitoba, and Ontario. When the PCPA negotiation subgroup was compared to the pre-pCPA era group, the proportion listed increased significantly in British Columbia, Saskatchewan, Manitoba and Newfoundland and Labrador, and time-to-listing increased significantly in New Brunswick and Nova Scotia and decreased significantly in Manitoba and Ontario. A sensitivity analysis suggested more favourable results regarding the pCPA's impact.

Conclusions: While the pCPA might have had a varied effect on time-to-listing, this study's primary analysis did not observe a significant impact on the overall proportion of new drug indications listed across jurisdictions. This may be due to the fact that, at the time of this study, only a limited number of drug indications had completed pCPA negotiations. This study provides a framework for future evaluations of the pCPA's impact as it continues to evolve.

\section{Strengths and limitations of this study}

- This was the first study to evaluate the real-world impact of a national pharmaceutical policy in Canada with respect to its stated aims of increasing access to drug treatment options and improving consistency of coverage across Canada.

- This study employed a robust analytical strategy consistent with that of a previous study that assessed the impact of the implementation of the Common Drug Review on drug coverage in Canada.

- Comprehensiveness: this study sampled both cancer and non-cancer drugs reviewed by Canadian national health technology assessment (HTA) agencies over a 6-year period and provided analyses for nine provincial jurisdictions across Canada which participate in the panCanadian Pharmaceutical Alliance.

- The study was conducted during early stages of the policy implementation, which meant the full extent of drug listing decision changes associated with the policy might not have yet been realised.

- Results of this study might be affected by inaccuracies or gaps in publicly accessible information regarding drug listing decisions, and the observed changes in drug listing decisions might be impacted by additional factors that this study did not adjust for, such as the evolution of the pan-Canadian Oncology Drug Review (pCODR) for centralised reviews of cancer drugs in Canada during the study period.

\section{INTRODUCTION}

Prescribed pharmaceuticals represent a significant proportion of healthcare spending in Canada, accounting for approximately $\$ 29.3$ billion $(13.9 \%)$ in 2013. Public drug programmes collectively fund the largest portion of this spending $\left(41.6 \%\right.$ in 2013), ${ }^{1}$ with federal, provincial, and territorial governments providing coverage through their 
specific formularies. ${ }^{2}$ Jurisdictions across the country have standardised the clinical and cost-effectiveness evaluation of drugs by implementing national health technology assessment (HTA) initiatives including the Common Drug Review (CDR) in 2003 and the pan-Canadian Oncology Drug Review (pCODR) in 2011.

Since 2006, it has become an increasingly common strategy for public drug programmes to negotiate a product listing agreement (PLA) with the drug manufacturer after a HTA review. ${ }^{3}$ In an attempt to consolidate the public sector's purchasing power of brand name drugs, premiers announced an agreement to establish a pan-Canadian Purchasing (later Pricing, now Pharmaceutical) Alliance (pCPA) in August 2010. An important goal of the pCPA is to achieve lower drug costs and consistent pricing across jurisdictions. ${ }^{4-6}$ The pCPA determines whether a joint pricing negotiation will occur for a drug indication after reviewing the final CDR or pCODR listing recommendation. A jurisdiction leading the negotiation then confirms participating jurisdictions with the manufacturer. If the negotiation reaches an agreement, the manufacturer and the lead jurisdiction sign a Letter of Intent (LOI); participating jurisdictions then use the LOI as the basis for a jurisdiction-specific PLA with the manufacturer. ${ }^{5}$ As of April 2014, the pCPA reported having completed 32 joint negotiations on brand name drugs, which led to an estimated $\$ 80$ million in annual savings. ${ }^{7}$ At the time of this writing, Quebec and federal drug plans did not participate in the pCPA, although Quebec has expressed its intent to join the pCPA (http://www.newswire.ca/fr/story/1420290/ provinces-and-territories-talk-health-care).

Beyond costs, other stated aims of the pCPA include increasing access to drug treatment options and improving consistency of drug coverage criteria across Canada. ${ }^{4-6}$ However, to date the authors of this study are unaware of any formal evaluation of the programme's impact on these aspects. Therefore, this study was conducted to compare the proportion of new drug indications listed and their time-to-listing in participating jurisdictions before and after establishment of the pCPA. Furthermore, this study also assessed the agreement between CDR/pCODR listing recommendations and listing decisions in individual jurisdictions.

\section{METHODS}

\section{Inclusion criteria}

This study adopted an analytical strategy similar to that of a previous study that compared drug coverage across Canada before and after the CDR was implemented. ${ }^{8} \mathrm{~A}$ study period of 1 September 2007-31 August 2013 (inclusive) was defined to include the 3 years before and 3 years after the establishment of the pCPA in August 2010. All drug indications that received a CDR or pCODR listing recommendation during the study period were identified according to information on the CDR and pCODR websites. In cases where a drug received multiple recommendations for the same indication, only the latest recommendation was included.

Each identified drug indication's listing status (and if listed, date of listing) as of the time of this study, 30 April 2014, on the formularies of the public drug plans and cancer agencies in nine pCPA-participating provincial jurisdictions (ie, all provinces except Quebec) was recorded. Listing status was determined by reviewing publicly accessible information from the provincial drug plans' formulary webpages and the pCODR's provincial funding summary documents.

\section{Study groups}

Drug indications that met the study inclusion criteria were categorised into two mutually exclusive groups: (1) drug indications with a listing recommendation issued between 1 September 2007 and 31 August 2010 ('pre-pCPA era' group) and (2) drug indications with a recommendation issued between 1 September 2010 and 31 August 2013 ('pCPA era' group). 1 September 2010 was used as the beginning date for the pCPA era according to information on the official website of the Council of the Federation, which stated that the pCPA was established in August 2010 by the Council of the Federation's Health Care Innovation Working Group (http://www.conseildelafederation.ca/en/initiatives/358pan-canadian-pricing-alliance). A subgroup of drug indications within the pCPA era group that had completed negotiations with the pCPA by the time of this study, 30 April 2014 ('pCPA negotiation' subgroup), was identified by reviewing information on the Council of the Federation website.

\section{Primary and subgroup analyses}

The primary analysis compared (1) the proportion of drug indications listed and (2) the time-to-listing in the nine jurisdictions between the pre-pCPA era group and the pCPA era group. The subgroup analysis compared these two outcomes between the pre-pCPA era group and the pCPA negotiation subgroup. A drug indication was considered 'listed' if it had a full (ie, a 'regular/ full/open/general benefit' or equivalent status) or any restricted listing status, including coverage under a special access programme (ie, a 'partial benefit', 'limited coverage/use', 'special authorisation', 'exceptional drug status', 'exceptional access programme' or similar status), on the formulary of a provincial drug plan or cancer agency as of 30 April 2014. Time-to-listing was evaluated as the number of calendar days between when a final CDR recommendation or pCODR notification to implement was issued and when the drug indication was listed by a jurisdiction. Time-to-listing values were reported in terms of medians rather than means, as means were affected by the presence of large value outliers in the data set. In infrequent instances where a jurisdiction listed a drug indication before the CDR or pCODR issued a listing recommendation for the drug indication $(n=20)$, such drug indications would have a 
negative time-to-listing and hence were excluded in evaluating medians of time-to-listing. These drug indications, however, were included in evaluating the proportion of drug indications listed. Fisher's exact test and the Mann-Whitney U test were performed using Minitab 17 (Minitab Inc, State College, Pennsylvania, USA) to assess the significance of differences in the proportion listed and time-to-listing, respectively.

\section{Agreement analysis}

For drug indications in the pre-pCPA era group, pCPA era group and pCPA negotiation subgroup, Fisher's exact test was performed to assess the association between $\mathrm{CDR} / \mathrm{pCODR}$ listing recommendations and listing decisions in each jurisdiction. The listing recommendations were categorised as either positive or negative, where a 'do not list' recommendation was considered negative and any other recommendation (including 'do not list at the submitted price') was considered positive.

\section{Sensitivity analyses}

Three sensitivity analyses were conducted to test the robustness of the study results. The first sensitivity analysis was conducted to account for the evolution of the pCPA process during the early stages of policy implementation. That is, while the pCPA was officially established in August 2010, the first pCPA negotiation was not reported until July 2011. Accordingly, the first sensitivity analysis repeated the primary analysis but excluded drug indications with a listing recommendation issued during the first 2 years of the pCPA era (1 September 2010-31 August 2012). To ensure a balanced comparison, the same analysis also excluded drug indications with a recommendation issued during the first 2 years of the pre-pCPA era (1 September 2007-31 August 2009). The second sensitivity analysis was conducted to examine if there were differences in the review processes for cancer drug indications (recommended by the pCODR) and non-cancer ones (CDR). This was carried out by comparing the proportion listed and time-to-listing for cancer versus non-cancer drug indications in the pCPA era group and the pCPA negotiation subgroup. Lastly, the third sensitivity analysis compared the proportion listed and time-to-listing for all drug indications included in the primary analysis in each jurisdiction year-over-year.

\section{RESULTS}

\section{Primary and subgroup analyses}

A total of 172 drug indications met the study inclusion criteria, of which 93 (54\%) were in the pCPA era group. Two drug indications in the pCPA era group were excluded from subsequent analyses, because as of 30 April 2014, pCPA negotiations for these two drug indications were still underway and as a result they were not yet eligible to receive jurisdictional listing decisions (see online supplementary appendix 1). As of 30 April 2014,
31 drug indications in the pCPA era group had completed PCPA negotiations and were thus assigned to the pCPA negotiation subgroup (see online supplementary appendix 1).

As of 30 April 2014, the jurisdictions listed $35-59 \%$ of drug indications in the pre-pCPA era group, and a nearly identical range, $36-59 \%$, in the pCPA era group; the jurisdictions listed $39-77 \%$ of drug indications in the pCPA negotiation subgroup (table 1). In the primary analysis comparing the pCPA era group to the pre-pCPA era group, the change in the proportion of drug indications listed was not significant for any jurisdiction. In the subgroup analysis which compared the pCPA negotiation subgroup to the pre-pCPA era group, however, the proportion listed increased significantly in British Columbia, Saskatchewan, Manitoba and Newfoundland and Labrador (table 1).

Across the jurisdictions, the range of the median time-to-listing for listed drug indications was 140-719 calendar days in the pre-pCPA era group, 131-457 days in the pCPA era group and 139-390 days in the pCPA negotiation subgroup (table 1). In the primary analysis comparing the pCPA era group to the pre-pCPA era group, the change in the median time-to-listing ranged from a decrease of 360 days in Manitoba to an increase of 88 days in New Brunswick and Newfoundland and Labrador (figure 1). Further, time-to-listing increased significantly in New Brunswick and decreased significantly in Alberta, Manitoba and Ontario (table 1). In the subgroup analysis which compared the pCPA negotiation subgroup to the pre-pCPA era group, the change in the median time-to-listing ranged from a decrease of 337 days in Prince Edward Island to an increase of 165 days in Newfoundland and Labrador (figure 1). For this comparison, time-to-listing increased significantly in New Brunswick and Nova Scotia and decreased significantly in Manitoba and Ontario (table 1).

\section{Agreement analysis}

Overall, there was a higher proportion of drug indications with a positive listing recommendation after establishment of the pCPA (40 such drug indications (51\%) in the pre-pCPA era group vs $60(65 \%)$ in the pCPA era group), although not statistically significant $(\mathrm{p}=0.38)$. In both the pre-pCPA and pCPA era groups, the proportion listed was significantly higher for drug indications with a positive listing recommendation than those with a negative recommendation in all the jurisdictions. In the pCPA negotiation subgroup, drug indications with a positive recommendation were significantly more likely to be listed than those with a negative recommendation in British Columbia, Saskatchewan and Newfoundland and Labrador (table 2).

\section{Sensitivity analyses}

In the first sensitivity analysis, changes in the results were observed after exclusion of drug indications that received a listing recommendation during the first 
Table 1 Proportion listed and median time-to-listing for all drug indications that received a CDR or pCODR listing recommendation between 1 September 2007 and 31 August 2013, before and after the establishment of the pCPA

\begin{tabular}{|c|c|c|c|c|c|c|c|c|c|c|}
\hline \multirow[b]{3}{*}{ Jurisdiction } & \multicolumn{5}{|c|}{ Number (\%) of drug indications listed } & \multicolumn{5}{|c|}{ Median time-to-listingt, calendar days } \\
\hline & \multirow[b]{2}{*}{$\begin{array}{c}\text { Pre-pCPA } \\
\text { era } \\
\text { All }(n=79)\end{array}$} & \multicolumn{2}{|c|}{ pCPA era§ } & \multicolumn{2}{|c|}{ p Valueף } & \multirow[b]{2}{*}{$\begin{array}{c}\text { Pre-pCPA } \\
\text { era } \\
\text { All }\end{array}$} & \multicolumn{2}{|c|}{ pCPA era§ } & \multicolumn{2}{|c|}{ p Value ${ }^{\star *}$} \\
\hline & & $\begin{array}{c}\text { All } \\
(n=91)\end{array}$ & $\begin{array}{c}\text { pCPA } \\
\text { negotiation } \\
\text { subgroup } \\
(n=31)\end{array}$ & $\begin{array}{l}\text { Pre-pCPA era vs } \\
\text { pCPA era }\end{array}$ & $\begin{array}{c}\text { Pre-pCPA era } \\
\text { vs pCPA } \\
\text { negotiation } \\
\text { subgroup }\end{array}$ & & All & $\begin{array}{c}\text { pCPA } \\
\text { negotiation } \\
\text { subgroup }\end{array}$ & $\begin{array}{c}\text { Pre-pCPA } \\
\text { era vs pCPA } \\
\text { era }\end{array}$ & $\begin{array}{c}\text { Pre-pCPA era } \\
\text { vs pCPA } \\
\text { negotiation } \\
\text { subgroup }\end{array}$ \\
\hline British Columbia & 37 (47\%) & $51(56 \%)$ & $24(77 \%)$ & 0.28 & $0.01^{*}$ & 267 & 268 & 275 & 0.34 & 0.67 \\
\hline Alberta & $36(46 \%)$ & $37(41 \%)$ & $18(58 \%)$ & 0.54 & 0.29 & 170 & 131 & 189 & $0.03^{*}$ & 0.85 \\
\hline Saskatchewan & $41(52 \%)$ & $54(59 \%)$ & 24 (77\%) & 0.36 & $0.02^{*}$ & 140 & 138 & 139 & 0.35 & 0.76 \\
\hline Manitoba & $31(39 \%)$ & $45(49 \%)$ & $21(68 \%)$ & 0.22 & $0.01^{*}$ & 701 & 341 & 390 & $<0.001^{*}$ & $0.001^{*}$ \\
\hline Ontario & $47(59 \%)$ & $54(59 \%)$ & $21(68 \%)$ & 1.00 & 0.52 & 447 & 223 & 246 & $0.001^{*}$ & $0.01^{*}$ \\
\hline New Brunswick & $41(52 \%)$ & $46(51 \%)$ & $19(61 \%)$ & 0.88 & 0.40 & 161 & 249 & 324 & $<0.001^{*}$ & $0.002^{*}$ \\
\hline Nova Scotia & $33(42 \%)$ & $38(42 \%)$ & $14(45 \%)$ & 1.00 & 0.83 & 155 & 197 & 237 & 0.30 & $0.02^{*}$ \\
\hline Prince Edward Island & $29(37 \%)$ & $33(36 \%)$ & $12(39 \%)$ & 1.00 & 1.00 & 719 & 457 & 383 & 0.07 & 0.06 \\
\hline $\begin{array}{l}\text { Newfoundland and } \\
\text { Labrador }\end{array}$ & $28(35 \%)$ & $38(42 \%)$ & $19(61 \%)$ & 0.43 & $0.02^{*}$ & 159 & 247 & 324 & 0.94 & 0.45 \\
\hline \multicolumn{11}{|c|}{ 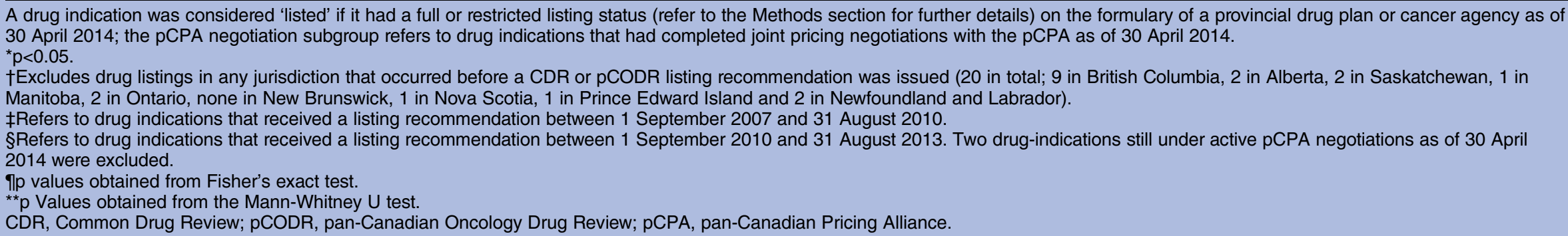 } \\
\hline
\end{tabular}




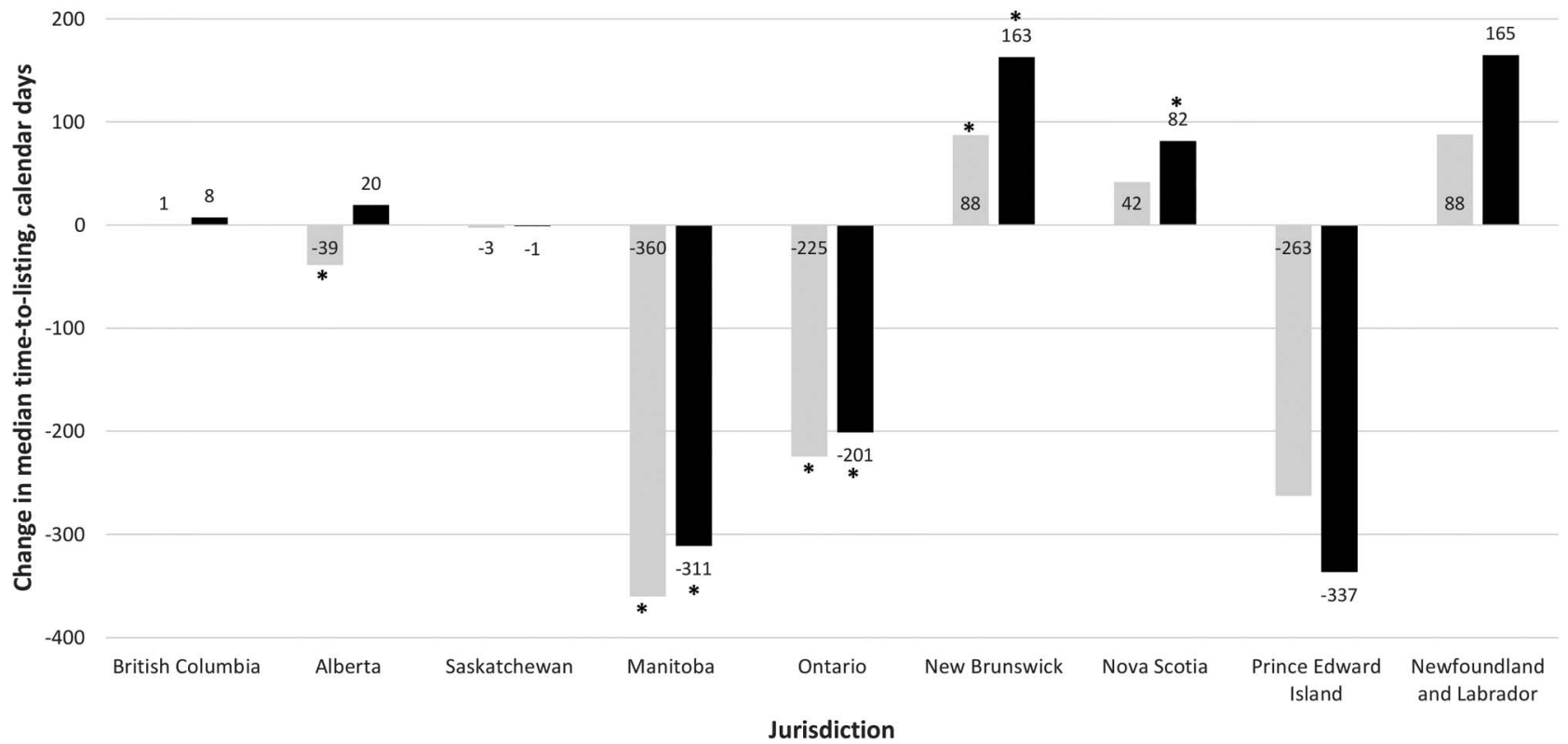

Figure 1 Change in median time-to-listing before and after the establishment of the $\mathrm{pCPA}$. Notes: Lighter columns=pCPA era group - pre-pCPA era group; darker columns=pCPA negotiation subgroup - pre-pCPA era group; refer to the Methods section for the groups' definitions. pCPA, pan-Canadian Pricing Alliance. ${ }^{*}$ Change in time-to-listing is significant as per the Mann-Whitney U test $(p<0.05)$.

2 years of the pCPA era (1 September 2010-31 August 2012) as well as those in the first 2 years of the pre-pCPA era (1 September 2007-31 August 2009). Comparing the pCPA era group to the pre-pCPA era group, the decrease in time-to-listing was no longer significant in Alberta, the increase in time-to-listing was no longer significant in New Brunswick, and there was a significant decrease in time-to-listing in Saskatchewan and Prince Edward Island. Comparing the pCPA negotiation subgroup to the pre-pCPA era group, there was a significant increase in the proportion listed in Alberta, New Brunswick, Nova Scotia and Prince Edward Island, a significant decrease in the time-to-listing in Saskatchewan and the increase in time-to-listing was no longer significant in New Brunswick or Nova Scotia (see online supplementary appendix 2).

In the second sensitivity analysis, the proportion listed in the pCPA era group and the pCPA negotiation subgroup was significantly higher for cancer than noncancer drug indications in all jurisdictions except Manitoba, Nova Scotia and Prince Edward Island. For both groups, no significant difference in time-to-listing between cancer and non-cancer drug indications was noted in any jurisdiction (see online supplementary appendices 3 and 4 ).

Lastly, there were no significant year-over-year changes in the proportion of drug indications listed in any jurisdiction. However, significant year-over-year changes in time-to-listing were observed in Alberta, Saskatchewan, Manitoba, New Brunswick, Prince Edward Island and Newfoundland and Labrador (table 3).

\section{DISCUSSION}

\section{Principal findings}

The primary analysis of this study did not show a significant change in the overall proportion of new drug indications listed in any jurisdiction after the establishment of the pCPA. Furthermore, the range in the overall proportion of new drug indications listed across jurisdictions remained essentially identical to that before the pCPA was established. However, it is worthwhile highlighting that only about one-third of the drug indications in the pCPA era group had completed pCPA negotiations at the time of this study. As a result, the number of drug indications that had completed pCPA negotiations during the first 3 years of the policy implementation might not be sufficient for a robust analysis of whether the pCPA's impact on the overall proportion of new drug indications listed across jurisdictions was statistically significant.

In a sensitivity analysis designed to account for the continued evolution of the pCPA during its early stages by conducting a narrower comparison of drug indications in the third year of the pCPA era to those in the past year of the pre-PCPA era, the proportion of drug indications listed increased significantly in almost all jurisdictions (eight out of nine). Additionally, in the subgroup analysis which compared only those drug indications in the pCPA era that had completed pCPA negotiations to drug indications in the pre-pCPA era, a significant increase in the proportion listed was observed in four out of nine jurisdictions. Taken together, these results suggest that there is promise for the pCPA to 


\begin{tabular}{|c|c|c|c|c|c|c|c|c|c|}
\hline \multirow[b]{3}{*}{ Jurisdiction } & \multirow{2}{*}{\multicolumn{3}{|c|}{$\begin{array}{c}\text { Pre-pCPA era† } \\
\text { All }\end{array}$}} & \multicolumn{6}{|c|}{ pCPA era‡ } \\
\hline & & & & \multicolumn{3}{|c|}{ All } & \multicolumn{3}{|c|}{ pCPA negotiation subgroup } \\
\hline & $\begin{array}{c}\text { Positive } \\
\text { recommendations } \S \\
(n=40)\end{array}$ & $\begin{array}{c}\text { Negative } \\
\text { recommendations } \rrbracket \\
(n=39)\end{array}$ & p Value ${ }^{\star *}$ & $\begin{array}{c}\text { Positive } \\
\text { recommendations§ } \\
(n=60)\end{array}$ & $\begin{array}{c}\text { Negative } \\
\text { recommendations } \\
(n=31)\end{array}$ & p Value e* $^{\star \star}$ & $\begin{array}{c}\text { Positive } \\
\text { recommendations§ } \\
(n=25)\end{array}$ & $\begin{array}{c}\text { Negative } \\
\text { recommendations } \\
(n=6)\end{array}$ & p Value ${ }^{\star *}$ \\
\hline British Columbia & $29(73 \%)$ & $8(21 \%)$ & $<0.001^{*}$ & $47(78 \%)$ & $4(13 \%)$ & $<0.001^{*}$ & $22(88 \%)$ & $2(33 \%)$ & $0.01^{*}$ \\
\hline Alberta & $30(75 \%)$ & $6(15 \%)$ & $<0.001^{*}$ & $35(58 \%)$ & $2(6 \%)$ & $<0.001^{*}$ & $17(68 \%)$ & $1(17 \%)$ & 0.06 \\
\hline Saskatchewan & $35(88 \%)$ & $6(15 \%)$ & $<0.001^{*}$ & $49(82 \%)$ & $5(16 \%)$ & $<0.001^{*}$ & $22(88 \%)$ & $2(33 \%)$ & $0.01^{*}$ \\
\hline Manitoba & $26(65 \%)$ & $5(13 \%)$ & $<0.001^{*}$ & $43(72 \%)$ & $2(6 \%)$ & $<0.001^{*}$ & $19(76 \%)$ & $2(33 \%)$ & 0.07 \\
\hline Ontario & $30(75 \%)$ & $17(44 \%)$ & $0.01^{*}$ & $46(77 \%)$ & $8(26 \%)$ & $<0.001^{*}$ & $19(76 \%)$ & $2(33 \%)$ & 0.07 \\
\hline New Brunswick & 38 (95\%) & $3(8 \%)$ & $<0.001^{*}$ & $43(72 \%)$ & $3(10 \%)$ & $<0.001^{*}$ & $17(68 \%)$ & $2(33 \%)$ & 0.17 \\
\hline Nova Scotia & $31(78 \%)$ & $2(5 \%)$ & $<0.001^{\star}$ & $36(60 \%)$ & $2(6 \%)$ & $<0.001^{*}$ & 13 (52\%) & $1(17 \%)$ & 0.19 \\
\hline $\begin{array}{l}\text { Prince Edward } \\
\text { Island }\end{array}$ & $28(70 \%)$ & $1(3 \%)$ & $<0.001^{*}$ & 32 (53\%) & $1(3 \%)$ & $<0.001^{*}$ & 11 (44\%) & $1(17 \%)$ & 0.36 \\
\hline $\begin{array}{l}\text { Newfoundland } \\
\text { and Labrador }\end{array}$ & $26(65 \%)$ & $2(5 \%)$ & $<0.001^{*}$ & $36(60 \%)$ & $2(6 \%)$ & $<0.001^{*}$ & $18(72 \%)$ & $1(17 \%)$ & $0.02^{*}$ \\
\hline \multicolumn{10}{|c|}{$\begin{array}{l}\text { The listing decision for a drug indication was considered positive if it had a full or restricted listing status (refer to the Methods section for further details) on the formulary of a provincial drug plan } \\
\text { or cancer agency as of } 30 \text { April } 2014 \text {; the pCPA negotiation subgroup refers to drug indications that had completed pricing negotiations with the pCPA as of } 30 \text { April } 2014 \text {. } \\
\text { * } p<0.05 \text {. } \\
\text { tRefers to drug indications that received a listing recommendation between } 1 \text { September } 2007 \text { and } 31 \text { August } 2010 \text {. } \\
\text { tRefers to drug indications that received a listing recommendation between } 1 \text { September } 2010 \text { and } 31 \text { August } 2013 \text {. Two drug-indications still under active pCPA negotiations as of } 30 \text { April } \\
2014 \text { were excluded. } \\
\text { \$Refers to any listing recommendation other than 'do not list'. } \\
\text { TRefers to a 'do not list' recommendation. }\end{array}$} \\
\hline
\end{tabular}


Table 3 Proportion listed and median time-to-listing for each year for drug indications that received a CDR or pCODR listing recommendation between September 1 , 2007 and August 31,2013 , before and after the establishment of the pCPA

\begin{tabular}{|c|c|c|c|c|c|c|c|c|c|c|c|c|}
\hline \multirow[b]{2}{*}{ Jurisdiction } & \multicolumn{6}{|c|}{ Number (\%) of drug indications listed } & \multicolumn{6}{|c|}{ Median time-to-listing*, calendar days } \\
\hline & $\begin{array}{c}1 \\
\text { September } \\
2007-31 \\
\text { August } \\
2008 \\
(n=26)\end{array}$ & $\begin{array}{c}1 \\
\text { September } \\
2008-31 \\
\text { August } \\
2009 \\
(n=26)\end{array}$ & $\begin{array}{c}1 \\
\text { September } \\
2009-31 \\
\text { August } \\
2010 \\
(n=27)\end{array}$ & $\begin{array}{c}1 \\
\text { September } \\
2010-31 \\
\text { August } \\
2011 \\
(n=16)\end{array}$ & $\begin{array}{c}1 \\
\text { September } \\
2011-31 \\
\text { August } \\
2012 \\
(n=43)\end{array}$ & $\begin{array}{c}1 \\
\text { September } \\
2012-31 \\
\text { August } \\
2013 \\
(n=32)\end{array}$ & $\begin{array}{c}1 \\
\text { September } \\
2007-31 \\
\text { August } \\
2008\end{array}$ & $\begin{array}{c}1 \\
\text { September } \\
2008-31 \\
\text { August } \\
2009\end{array}$ & $\begin{array}{c}1 \\
\text { September } \\
2009-31 \\
\text { August } \\
2010\end{array}$ & $\begin{array}{c}1 \\
\text { September } \\
2010-31 \\
\text { August } \\
2011\end{array}$ & $\begin{array}{c}1 \\
\text { September } \\
2011-31 \\
\text { August } \\
2012\end{array}$ & $\begin{array}{c}1 \\
\text { September } \\
2012-31 \\
\text { August } \\
2013\end{array}$ \\
\hline $\begin{array}{l}\text { British } \\
\text { Columbia }\end{array}$ & $9(35 \%)$ & $13(50 \%)$ & $15(56 \%)$ & $11(69 \%)$ & $25(58 \%)$ & $15(47 \%)$ & 356 & 407 & 265 & 272 & 270 & 228 \\
\hline Alberta & $10(38 \%)$ & $14(54 \%)$ & $12(44 \%)$ & $9(56 \%)$ & $16(37 \%)$ & $12(38 \%)$ & 320 & $133 \dagger$ & 216 & 129 & 147 & 134 \\
\hline Saskatchewan & $10(38 \%)$ & $16(62 \%)$ & $15(56 \%)$ & $9(56 \%)$ & $27(63 \%)$ & $18(56 \%)$ & 140 & 106 & $290 \dagger$ & $93 \dagger$ & 149 & 139 \\
\hline Manitoba & $8(31 \%)$ & $9(35 \%)$ & $14(52 \%)$ & $7(44 \%)$ & $25(58 \%)$ & $13(41 \%)$ & 278 & 567 & 993† & 463† & 352 & 252 \\
\hline Ontario & $12(46 \%)$ & $15(58 \%)$ & 20 (74\%) & $13(81 \%)$ & $25(58 \%)$ & $16(50 \%)$ & 408 & 540 & 519 & 316 & 226 & 160 \\
\hline New & 12 (46\%) & $16(62 \%)$ & $13(48 \%)$ & $8(50 \%)$ & 25 (58\%) & $13(41 \%)$ & 179 & $147 \dagger$ & 148 & 217 & 284 & 252 \\
\hline \multicolumn{13}{|l|}{ Brunswick } \\
\hline Nova Scotia & $9(35 \%)$ & $14(54 \%)$ & $10(37 \%)$ & $8(50 \%)$ & $21(49 \%)$ & $9(28 \%)$ & 87 & 161 & 162 & 129 & 199 & 203 \\
\hline $\begin{array}{l}\text { Prince Edward } \\
\text { Island }\end{array}$ & $12(46 \%)$ & $10(38 \%)$ & $7(26 \%)$ & 7 (44\%) & $18(42 \%)$ & $8(25 \%)$ & 601 & 788 & 425 & 806 & $439+$ & 326 \\
\hline $\begin{array}{l}\text { Newfoundland } \\
\text { and Labrador }\end{array}$ & 7 (27\%) & $12(46 \%)$ & $9(33 \%)$ & 7 (44\%) & $20(47 \%)$ & 11 (34\%) & 339 & $107 \dagger$ & 159 & 250 & 116 & 319 \\
\hline
\end{tabular}


have a positive impact on the proportion of new drug indications listed in participating jurisdictions.

In terms of time-to-listing, the primary analysis showed that the establishment of the pCPA was associated with significant and varied changes in time-to-listing in several jurisdictions. In the sensitivity analysis that compared drug indications in the third year of the pCPA era to those in the last year of the pre-PCPA era, the results indicated that the impact of the pCPA on the time-to-listing was a reduction in four out of nine jurisdictions.

Lastly, the agreement analysis showed that drug listing decisions in participating jurisdictions were generally in agreement with CDR/pCODR listing recommendations, both before and after the pCPA was established.

\section{Strengths and limitations}

This study employed a robust analytical strategy consistent with that of a previous study that assessed the impact of the CDR implementation on drug coverage in Canada. ${ }^{8}$ Furthermore, this study sampled a comprehensive list of both cancer and non-cancer drugs reviewed by Canadian national HTA agencies over a 6-year period and provided analyses for nine provincial jurisdictions.

This study had several limitations. First, the accuracy of its results might be affected by potential inaccuracies or gaps in publicly accessible information regarding funding approvals for new drug indications, dates of approvals and which jurisdictions actually participated in specific pCPA negotiations. Currently, no public information is available regarding when each pCPA negotiation was initiated or finalised and details concerning jurisdiction-specific PLAs conducted outside of the pCPA were not available. Second, as the study was conducted during the early stages of the pCPA, the jurisdictions had less time after listing recommendations were issued to make listing decisions for drug indications in the pCPA era group versus those in the pre-pCPA era group. This may have led to an underestimation of the proportion listed and time-to-listing results for the pCPA era group and the pCPA negotiation subgroup. Additionally, negotiations by pCPA-participating jurisdictions were an evolving process, which may again have contributed to an underestimation of the extent of listing decision changes associated with the pCPA; however, with the understanding that the first pCPA negotiation was reported in July 2011, this study conducted a sensitivity analysis to account for institutional adjustments during the start-up phase of the pCPA. Furthermore, the smaller sample size of the PCPA negotiation subgroup, due to the limited number of drugs that had been selected for and completed pCPA negotiations, might have resulted in a lack of power to reach statistical significance in some analyses. Lastly, the analysis did not adjust for additional factors, such as evolution of the CDR and pCODR operating procedures during the study period, fiscal circumstances and drug plan budgets of the jurisdictions, inter-jurisdictional differences in drug reimbursement decision-making processes, the disease area and patient eligibility criteria of a drug, drug prices and price discounts in pricing negotiations, which might have confounded the reported changes in drug listings after the pCPA was established. For example, cancer drug indications accounted for a small proportion of the pre-pCPA era group but close to half of the pCPA negotiation subgroup (see online supplementary appendix 4 ). Therefore, the reported differences in the proportion listed and time-to-listing between these two study groups might be partly due to jurisdictions' priorities on providing timely access to anticancer drugs, such as through establishing the pCODR process in 2010 for centralised reviews of cancer drugs in Canada and granting coverage for cancer drugs under jurisdictional special access programmes.

\section{Comparison with other studies}

To the authors' knowledge, no peer-reviewed publications have evaluated the impact of the pCPA on drug listings across Canada; however, two research abstracts recently evaluated this topic. One abstract reported no significant year-over-year changes in time-to-listing of non-cancer drugs in Ontario between 2008 and 2012, ${ }^{9}$ consistent with this study's year-over-year results for Ontario. The other abstract reported that between 2010 and 2014, non-cancer drugs that entered pCPA negotiations generally had a longer time-to-listing compared with those not selected for negotiations; however, no statistical test of the significance of the difference in time-to-listing was provided. ${ }^{10}$

\section{Conclusion and implications for policy and future research}

It is important to evaluate the impact of health policy initiatives against stated objectives in the real-world setting. The stated aims of the pCPA include increasing access to drug treatment options, achieving lower drug costs and consistent pricing, and improving consistency of coverage criteria across Canada. Despite still being in a formative stage, the pCPA has reported achieving significant drug cost savings. This study provides insight during the early stage of implementation concerning the pCPA's additional aims of increasing access to drug treatment options and improving consistency of coverage across Canada. The study's findings suggest that, at this time, the establishment of the pCPA process is not yet associated with significant changes in the overall proportion of new drug indications listed in participating jurisdictions or improved consistency in overall listing decisions across jurisdictions. It is, however, associated with significant and varied changes in time-to-listing in some participating jurisdictions. Our subgroup and sensitivity analyses did suggest that there is promise for the pCPA to improve the proportion of new drug indications listed and reduce the time-to-listing in jurisdictions.

As jurisdictions move forward to develop a formal governance model for the pCPA process (eg, the secretariat model recommended by the Health Care Innovation Working Group (HCIWG) in the Pan Canadian Drugs Negotiations Report (ie, the 'IBM Report') ${ }^{11}$ ) and continue to build the institutional capacities of the pCPA, it 
can be expected that a higher proportion of new drug indications will go through the pCPA process, thereby allowing the pCPA to have a greater impact on drug listing decisions across jurisdictions. Therefore, there is an important need for continued monitoring and evaluation of the pCPA's performance and outcomes as its practices continue to mature in the years to come. The current analysis provides a quantitative framework for future evaluation of the impact of the pCPA. The need for performance assessment has been recognised by the pCPA. A key recommendation of the Pan Canadian Drugs Negotiations Report is to develop and use metrics to evaluate and benchmark the PCPA performance. ${ }^{11}$ Such metrics, to be developed jointly with stakeholders including drug manufacturers and patient groups, ${ }^{11}$ may create further incentives and interests in achieving the performance measures.

Another important need as highlighted by this current study is improved transparency around pCPA processes, criteria and timelines. As highlighted in the discussion of study limitations above, this study's results might be affected by a lack of publicly accessible information regarding the participants, timelines and criteria of joint negotiations. Such information, if available, may allow future research to identify key drivers of the pCPA's outcomes and additional factors that affect patient access and drug costs after pCPA negotiations. The need for improved transparency has also been acknowledged by the pCPA. For example, the Pan Canadian Drugs Negotiations Report has recommended enhanced communication of pCPA processes, timelines, past drug negotiations statistics and benchmarks through the official pCPA website. ${ }^{11}$

Furthermore, it is important for future research to investigate how interjurisdictional differences in reimbursement decision-making processes may affect consistency in reimbursement decisions across jurisdictions. As acknowledged above, this current study did not adjust for factors such as jurisdiction-specific processes in the analysis. Although success through pCPA may bring Canada a step closer to the goals of improved access to drug treatment options and pharmaceutical cost savings, there are still jurisdictional specific issues that will continue to impact patient access and costs. Further research may uncover important insights regarding how to address such interjurisdictional differences.

Lastly, it will also be important for future research to compare the Canadian approach to pharmaceutical policy interventions adopted in other countries. Such analyses may yield valuable insights for pharmaceutical policymakers regarding the design of effective policy interventions.

\author{
Author affiliations \\ ${ }^{1}$ MILLREED Enterprises Ltd, Toronto, Ontario, Canada \\ ${ }^{2}$ J.Venkatesh Healthcare Consulting Inc, Surrey, British Columbia, Canada \\ ${ }^{3}$ Janssen Inc, Toronto, Ontario, Canada \\ ${ }^{4}$ Cornerstone Research Group Inc, Burlington, Ontario, Canada \\ ${ }^{5}$ School of Public Health, University of Alberta, Edmonton, Alberta, Canada
}

Acknowledgements The authors would like to thank Aron Quah for his time and efforts in compiling the listing recommendation and jurisdictional listing decision data for the study analysis. The authors would like to thank Dana Anger for constructive discussions on the study design and for her time and assistance in editing the manuscript. The authors thank Emmanuel Ewara for helpful discussion on the topic.

Contributors ZS and MT conducted statistical analyses. DM, JV, DE, MT and ZS interpreted analysis results. DM, ZS and MT wrote the first draft. JV, RY and DE revised the manuscript critically for important intellectual content. All authors participated in the design of the study. All authors read and approved the final manuscript. All authors have agreed to act as guarantor of the work and accept full responsibility for the work, had access to the data and controlled the decision to publish.

Funding Funding for this project was provided by Janssen Inc. The funding organisation had no influence on the conduct of the analyses or the interpretation of the study results. DE is a Canada Research Chair in chronic disease prevention and management funded by the Government of Canada.

Competing interests We have read and understood BMJ's policy on declaration of interests and declare the following: DM and JV work as consultants for both public and private sector organisations; RY works for Janssen Inc; ZS and MT work as consultants for private sector organizations in the healthcare industry.

Provenance and peer review Not commissioned; externally peer reviewed.

Data sharing statement No additional data are available.

Open Access This is an Open Access article distributed in accordance with the Creative Commons Attribution Non Commercial (CC BY-NC 4.0) license, which permits others to distribute, remix, adapt, build upon this work noncommercially, and license their derivative works on different terms, provided the original work is properly cited and the use is non-commercial. See: http:// creativecommons.org/licenses/by-nc/4.0/

\section{REFERENCES}

1. Prescribed drug spending in Canada, 2012: a focus on public drug programs. Ottawa, Ontario: Canadian Institute for Health Information, 2014. https://secure.cihi.ca/free_products/Prescribed_Drug Spending_in_Canada_EN.pdf (accessed 26 Aug 2014).

2. Health care system-access to insurance coverage for prescription medicines. Ottawa, Ontario: Health Canada, 2004. http://www.hc-sc. gc.ca/hcs-sss/pharma/acces/index-eng.php (accessed 26 Aug 2014).

3. Morgan SG, Friesen MK, Thomson PA, et al. Use of product listing agreements by Canadian provincial drug benefit plans. Healthc Policy 2013;8:45-55.

4. Premiers protecting Canada's health care systems. Ottawa, Ontario: Council of the Federation, 2010. http://www.conseildelafederation.ca/ en/latest-news/17-2010/153-premiers-protecting-canada-s-healthcare-systems (accessed 26 Aug 2014).

5. Scope of pan-Canadian pricing alliance process. Ottawa, Ontario: Council of the Federation, 2014. http://www.conseildelafederation.ca/ phocadownload/pcpa/scope of_pcpa_process_2014.pdf (accessed 26 Aug 2014).

6. Initiatives-pan-Canadian pricing alliance. Ottawa, Ontario: Council of the Federation, 2013. http://www.conseildelafederation.ca/en/initiatives/ 358-pan-canadian-pricing-alliance (accessed 26 Aug 2014).

7. Fact sheet on pan-Canadian pharmaceutical initiatives. Ottawa, Ontario: Council of the Federation, 2014. http://www. conseildelafederation.ca/en/latest-news/74-2014/370-fact-sheet-onpan-canadian-pharmaceutical-initiatives (accessed 26 Aug 2014).

8. Gamble JM, Weir DL, Johnson JA, et al. Analysis of drug coverage before and after the implementation of Canada's Common Drug Review. CMAJ 2011:183:E1259-66.

9. Robertson $\mathrm{C}$, Zhang $\mathrm{Y}$, Bosnic N. Impact of the pan Canadian pricing alliance on time to listing in Canada. Value in Health 2014;17:A24

10. Luciani L, Gregory V, Barbeau M. Impact of the pan-Canadian Pricing Alliance (pCPA) on access to drug treatment options for Canadian patients. Value in Health 2014;17:A147.

11. Pan Canadian Drugs Negotiations Report. Ottawa, Ontario: Health Care Innovation Working Group, 2014. http://www.conseildelafederation.ca/ phocadownload/pcpa/pan canadian drugs negotiations report march22_2014.pdf (accessed 21 Oct 2014). 